\title{
Reconfiguraciones identitarias en la Asociación Madres de Plaza de Mayo: lucha contra la impunidad, radicalización y "giro a la izquierda" (1983-2003)
}

\author{
Identity reconfigurations in the Mothers of Plaza de Mayo Association: fight \\ against impunity, radicalization and "turn to the left" (1983-2003)
}

\author{
Virginia Morales*
}

\begin{abstract}
Resumen: Luego de finalizada la última dictadura cívico-militar, las Madres de Plaza de Mayo dieron inicio a una nueva etapa de lucha contra la impunidad que las posicionó en confrontación con los gobiernos que hegemonizaron la Argentina hasta los primeros años del siglo XXI. A partir de un análisis político del discurso, en este artículo nos detendremos en el análisis de las reconfiguraciones identitarias de la Asociación Madres de Plaza de Mayo entre los años 1983 y 2003. Para ello indagaremos en la radicalidad que alcanzó su lucha en el período mencionado y en los nuevos contenidos y referentes que se inscribieron durante su resistencia al neoliberalismo.
\end{abstract}

Palabras clave: Asociación Madres de Plaza de Mayo, identidad, democracia, impunidad, neoliberalismo, radicalidad.

\begin{abstract}
After the last civil-military dictatorship, the Mothers of Plaza de Mayo began a new stage of struggle against impunity that placed them in confrontation with the governments that hegemonized Argentina until the first years of the 21st century. From a political analysis of the discourse, in this article we will stop in the analysis of the identity reconfigurations of the Mothers Association of Plaza de Mayo between the years 1983 and 2003. For this we will inquire into the radicality that reached its struggle in the mentioned period and in the new contents and referents that were inscribed during their resistance to neoliberalism.
\end{abstract}

Keywords: Mothers of Plaza de Mayo Association, identity, democracy, impunity, neoliberalism, radicalism.

Recibido: 31 diciembre 2016

Aceptado: 13 marzo 2017

\footnotetext{
* Argentina. Licenciada y Doctora en Ciencia Política. Concejo Nacional de Investigaciones Científicas y Técnicas, Universidad Nacional de Villa María (CONICET-UNVM). E-mail: mvirginiamorales22@gmail.com
} 
Cuando a veces somos tan criticonas y tan radicalizadas y tan fuertes, no hay otro camino. A veces pensamos que no hay otro camino, no hay otro discurso posible [...] Todos los jueces son de la dictadura. Son los mismos. [...] Las Madres no nos olvidamos de los que golpearon la puerta de los cuarteles, que eran políticos. No nos olvidamos de los que hicieron obediencia debida y punto final. No nos olvidamos de los que hicieron el indulto. ${ }^{l}$

\section{Introducción}

El 10 de diciembre de 1983 asume al Poder Ejecutivo el presidente electo Raúl Alfonsín y con ello retorna la democracia en la Argentina luego de una de las dictaduras cívicomilitares más cruentas de toda América Latina. Con 30.000 detenidos-desaparecidos, centenares de centros clandestinos de detención y torturas, presos políticos y una resistencia al gobierno de facto protagonizada por el Movimiento de Derechos Humanos (MDH) en el que convergieron las principales fuerzas políticas y sociales del país, la emergente democracia se constituía no sólo en la salida del horror producida por el terrorismo de Estado, sino también en la superficie de inscripción de múltiples demandas y expectativas.

Durante la transición política, los organismos de derechos humanos alcanzaron un protagonismo inusitado. El conflicto por los derechos humanos se intensificó y alcanzó una visibilidad pública que lo conformó en uno de los temas más decisivos de aquel momento. A su vez, dentro del MDH, la confrontación que establecieron las Madres de Plaza de Mayo $^{2}$ con la dictadura les otorgó una significativa relevancia. Su lucha trascendió a nivel internacional convirtiéndolas en un emblema en la defensa de los derechos humanos, mientras que a nivel nacional encabezaron todas las manifestaciones de repudio al gobierno

\footnotetext{
${ }^{1}$ Hebe de Bonafini, Buenos Aires, 30-05-1998.

${ }^{2}$ El gobierno militar implementó una serie de metodologías represivas como detenciones ilegales, torturas, asesinatos y desapariciones de personas. En un clima de silencio respecto de estas metodologías, muchas madres emprendieron la búsqueda de sus hijos desaparecidos por diversas instituciones. En sus recorridos diarios, no sólo no recibieron respuestas respecto de lo acontecido con ellos, sino que se encontraban cada día con un número mayor de madres en la misma situación, de modo tal que de sus encuentros en la búsqueda individual comenzaron a emerger sentimientos de solidaridad, contención e igualdad entre ellas. Luego de múltiples fracasos solitarios de búsqueda, decidieron concurrir a la Plaza de Mayo el 30-04-1977 para redactar una carta al presidente de facto con la pregunta respecto de lo ocurrido con sus hijos. De este modo se conforma el proceso de emergencia de las "Madres de Plaza de Mayo" y de búsqueda colectiva de sus desaparecidos. Véase Ulises Gorini, La rebelión de las Madres: Historia de las Madre de Plaza de Mayo (1976-1983), Buenos Aires, Norma, 2006 y Virginia Morales, De la cocina a la Plaza. La categoría "madre" en el discurso de las Madres de Plaza de Mayo, Villa María, Editorial Universitaria Villa María, 2010.
} 
de facto, alcanzaron un masivo apoyo ciudadano y sus demandas de verdad y justicia dominaron el debate político de la campaña electoral.

Ahora bien, una vez restablecido el Estado de Derecho, las Madres confrontaron con el nuevo gobierno, con las políticas en materia de derechos humanos que éste implementó $\mathrm{y}$, en términos más generales, con el sistema democrático que el mismo constituyó. Se inició así, para este organismo, una nueva etapa de lucha contra la impunidad que hegemonizará su lucha hasta los primeros años del nuevo siglo y que las posicionará en disputa no sólo con los gobiernos constitucionales sino también con las políticas de revisión del pasado más reciente que éstos impulsaron y con el proyecto económico neoliberal que desembarcó en el país fuertemente durante la década del noventa. Pero, ¿cómo comprender los términos de la lucha contra la impunidad que las Madres llevaron adelante y su confrontación con las formaciones políticas mencionadas? ¿Cómo se constituyó su resistencia a las políticas neoliberales? ¿Cómo articularon esta resistencia con su lucha contra la impunidad? ¿Qué efectos trajo aparejados esta redefinición de su lucha para la dimensión identitaria del organismo? ¿Qué repercusiones trajo esta nueva confrontación sobre el lugar protagónico y emblemático que habían alcanzado las Madres durante la resistencia a la dictadura y el período de transición? Partiendo de estos interrogantes, en este artículo analizaremos las reconfiguraciones identitarias que se produjeron en la Asociación Madres de Plaza de Mayo (AMPM) ${ }^{3}$ entre los años 1983 y 2003. Sostendremos que estas reconfiguraciones estuvieron atravesadas por un proceso de radicalización que implicó la incorporación de nuevos contenidos y referentes a su lucha como así también la conformación de nuevos espacios de construcción política en los que la confrontación con el Estado y la forma que adquirió el sistema político post-dictatorial resultaron centrales.

Dentro de las múltiples investigaciones sociales que analizan a las Madres, se destacan aquellas que indagan en la emergencia del organismo en dictadura y su devenir durante los primeros años de la democracia. Una parte considerable de éstas últimas, giran en torno al posicionamiento que adoptaron ante los gobiernos constitucionales destacando

\footnotetext{
${ }^{3}$ La AMPM -liderada hasta la actualidad por Hebe de Bonafini- se conformó en 1986 luego de la división que se produjo en el organismo de Madres originado en abril de 1977. De esta ruptura, además, se constituyó Madres de Plaza de Mayo Línea Fundadora -con Nora Cortiñas, Marta Vázquez y "Taty" Almeida como sus principales exponentes-. Nos circunscribiremos en estas páginas a la Asociación por cuanto ha sido el organismo en el que la radicalización adquirió mayor fuerza. En este sentido, nos interesa reflexionar sobre los siguientes interrogantes: ¿en qué consiste esa radicalidad? ¿cuáles fueron las condiciones que la hicieron posible? ¿cómo afectó dicha radicalidad a la lucha que llevaron adelante durante la resistencia a la dictadura? Hemos trabajado con detenimiento la división del organismo y su importancia para pensar la reconfiguración identitaria durante el alfonsinismo en Virginia Morales, "Escisión y dos modos de ser Madres de Plaza de Mayo: tensión y complejidad en la socialización de la maternidad", Estudios de Género, 3:6, julio-diciembre 2017, 68-105. Asimismo, cabe destacar que este artículo considera como período temporal el retorno a la democracia y no la conformación de la AMPM por cuanto consideramos que el lugar en el escenario sociopolítico que adoptó Madres de Plaza de Mayo los años previos a la división -si bien con tensiones hacia su interior- estuvo hegemonizado por el grupo de mujeres-madres que luego constituirá la Asociación.
} 
una radicalización de su lucha desde la que fundamentan la pérdida de protagonismo del organismo y la emergencia de un discurso antidemocrático. ${ }^{4}$ Uno de los principales puntos desde los que se analiza dicha radicalización repara en las nuevas relaciones que establecieron los organismos de derechos humanos, y en especial la Asociación Madres de Plaza de Mayo (AMPM), con organizaciones militantes de izquierda y con el lenguaje político que los nutre. Esta lectura, de manera más o menos explícita, se diseminó entre la literatura especializada al punto tal que el avance de los años de democracia es correlativo al incremento del desinterés por el estudio del desarrollo de la lucha de las Madres. En este sentido, Elizabeth Borland destaca que no se ha indagado con profundidad y sistematicidad respecto de cómo han ampliado sus objetivos para incluir temas tan diversos como la deuda externa, el hambre, el desempleo y la corrupción. ${ }^{5}$

A partir de lo dicho, este artículo vuelve sobre las lecturas que comprenden la radicalidad de la AMPM en los términos recién mencionado y aborda un momento de lucha que ha sido por estudiado, tanto como efecto de estas lecturas como del lugar marginal que ocuparon los derechos humanos en la formación política de la década del noventa. Consideramos relevante volver sobre estas interpretaciones debido a que no sólo proliferaron en ámbitos académicos durante la temprana democracia, sino que también adquirieron relevancia durante la década siguiente entre una parte considerable de las fuerzas sociopolíticas dominantes del país, del periodismo y de la opinión pública.

No obstante, es necesario considerar que algunos estudios han avanzado sobre la radicalidad que aquí nos interesa y sobre el desarrollo del organismo en democracia. En este sentido, Viano ${ }^{6}$ considera el giro a la izquierda de las Madres a partir de la historia oral

\footnotetext{
${ }^{4}$ Martín D’Alessandro, "Los movimientos sociales en la transición democrática: El caso de las Madres de Plaza de Mayo: sentimiento y discurso", América Latina Hoy, 20, 1998, 41-45; Héctor Leis, El movimiento por los derechos humanos y la política argentina/l, Buenos Aires, Centro Editor de América Latina, 1989; Carlos Brocato, "De la ética a la política", La Mirada, 1, 1990, 1216 y Sebastián Pereyra, "¿Cuál es el legado del movimiento de Derechos Humanos?: El problema de la impunidad y los reclamos de justicia en los noventa", Federico Schuster, Francisco Naishtat, Gabriel Nardacchione y Sebastián Pereyra (comps.), Tomar la palabra: Estudios sobre protesta social y acción colectiva en la Argentina contemporánea, Buenos Aires, Prometeo, 2005, 151-191.

${ }^{5}$ Elizabeth Borland, "Las Madres de Plaza de Mayo en la era neoliberal: Ampliando objetivos para unir el pasado, el presente y el futuro". Colombia Internacional, 63, Colombia, 2006, 128-147. Cabe destacar que durante la última década se produjo una proliferación de los estudios sobre las Madres. No obstante, ello no implicó volver sobre aspectos poco estudiados de su lucha, sino que más bien, estos estudios estuvieron circunscriptos al posicionamiento de los organismos de derechos humanos frente al Estado y las políticas desarrolladas por los gobiernos de Néstor Kirchner (2003-2007) y Cristina Fernández de Kirchner (2007-2015), y al análisis de las disputas por la memoria y las representaciones del pasado reciente que tuvieron lugar durante estas gestiones gubernamentales.

6 Cristina Viano, "Trabajadora, militante y madre: una historia de vida, X Jornadas Interescuelas/Departamentos de Historia. Escurla de Historia de la Facultad de Humanidades y Artes, Universidad Nacional de Rosario, Rosario, 2005 y "Mujeres y movimientos sociales: un acercamiento a Madres de Plaza de Mayo desde una historia de vida", Gerardo Necoechea,
} 
y del análisis de prácticas político-partidarias de las mujeres-madres anteriores a su constitución en Madres de Plaza de Mayo. Por su parte, D’Antornio ${ }^{7}$ argumenta que la fuerza anticapitalista y la lucha por el socialismo de la AMPM no puede pensarse escindida de la radicalidad con la que estas mujeres utilizan el maternaje. Una radicalidad que condujo al organismo a iniciar prácticas que albergan un potencial revolucionario y a conformar una experiencia política inconmensurable y sin antecedentes. En continuidad con estas lecturas, analizaremos las reconfiguraciones identitarias que se produjeron en la AMPM durante el período en cuestión a partir de un análisis discursivo que se nutre de diferentes estrategias de investigación que se derivan de los presupuestos ontológicos de la Teoría del Discurso Político. Al respecto, este enfoque parte de una concepción discursiva de lo social y las identidades, lo cual implica tanto una concepción performativa del lenguaje como una noción amplia y particular de discurso en la que no hay una distinción entre elementos lingüísticos y extra-lingüísticos. Esta concepción habilita a considerar la lucha de las MPM en términos discursivos de manera tal que metodológicamente se incorporan al análisis una serie de acciones que no serán consideradas como una mera descripción de los hechos sino como parte de su discurso, esto es, como acciones portadoras de sentido que adquieren relevancia para el análisis al igual que las diferentes fuentes en donde se recuperará la voz de las Madres.

De esta manera, en una primera instancia presentaremos la perspectiva conceptual en la que se inscribe nuestro análisis. Aquí cobrará relevancia el concepto de articulación desarrollado por Ernesto Laclau y Chantal Mouffe y la concepción discursiva de lo social que los mismos proponen. Ello nos habilitará a comprender la lucha e identidad de las Madres en términos de un proceso de articulación política contingente. Seguidamente, indagaremos en estos procesos articulatorios y en las diferentes formas en que se fueron reconfigurando durante las tres décadas de democracia que sucedieron a la última dictadura. Así, analizaremos la nueva etapa de lucha contra la impunidad que conforma el organismo en oposición a la configuración política alfonsinista, mientras que finalizaremos este escrito centrándonos en los desplazamientos y resignificaciones que dieron emergencia a un nuevo momento de lucha en el que la confrontación con el neoliberalismo y la emergencia de una lucha por las condiciones estructurales que hacen posibles las vidas serán los aspectos que definirán el nuevo protagonismo que alcanzó la AMPM durante los primeros años del nuevo siglo.

\section{Confrontación y radicalidad en la nueva etapa de lucha contra la impunidad}

Mariana Mastrángelo, Edna Ovalle, et. al., Historia Oral y militancia política en México y Argentina, Buenos Aires, El Colectivo, 2008.

${ }^{7}$ Débora D’Antonio, "Las Madres de Plaza de Mayo y las aperturas de un camino de resistencias. Argentina, última dictadura militar: 1976-1983", Nuestra América, 2, agosto-diciembre, 2006, 2940. 
La perspectiva analítica desarrollada por Ernesto Laclau y Chantal Mouffe parte de considerar que todo objeto y práctica tiene un significado que se define de manera relacional, contextual y contingente. Lo social es concebido como un espacio discursivo, como una totalidad estructurada de modo parcial y precario que se instituye por medio de discursos sociales que dan sentido al orden social. Con lo cual, "toda configuración social es una configuración significativa". ${ }^{8}$ Ahora bien, dicha institución nunca puede ser total ya que siempre está rodeada por un campo de discursividad que la sobrepasa y pone al descubierto su radical contingencia. La institución de lo social, así, es el resultado de un proceso de lucha y construcción política en la que los diferentes discursos compiten por producir y fijar el sentido de lo social de modo tal que toda configuración discursiva está atravesada por relaciones de poder y antagonismo. En términos de Laclau, toda objetividad, toda constitución discursiva, es un acto de poder. Esto implica, por una parte, que toda objetividad es una objetividad amenazada $\mathrm{y}$, por la otra, que si a pesar de ello puede afirmarse parcialmente como objetividad, esto sólo puede darse sobre la base de reprimir aquello que la amenaza.

Si el poder es condición de posibilidad de toda configuración social, toda significación o identidad que tenga lugar dentro de una formación discursiva particular, no será un punto homogéneo sino un conjunto articulado de elementos. La fijación del sentido de lo social es como dijimos siempre parcial y contingente, a la vez que involucra la puesta en marcha de prácticas articulatorias a través de las cuales se establecen relaciones entre los elementos de manera tal que su identidad es modificada como resultado de estas prácticas. ${ }^{9}$ Es decir,

[a]unque no existe un vínculo necesario entre las diferentes posiciones de sujeto, en el campo de la política siempre hay discursos que tratan de proveer una articulación entre ellas desde diferentes puntos de partida. Por eso cada posición de sujeto se constituye dentro de una estructura discursiva esencialmente inestable, puesto que se somete a una variedad de prácticas articulatorias que constantemente la subvierten y transforman. Por eso no hay ninguna posición de sujeto cuyos vínculos con estas estén asegurados de manera definitiva y, por lo tanto, no hay identidad social que pueda ser completa y permanentemente adquirida. ${ }^{10}$

Por lo tanto, la articulación no es una relación de necesidad, sino que más bien pone de manifiesto la inexistencia de todo vínculo a priori entre elementos, entre significantes y significado y entre posiciones de sujetos. Las prácticas articulatorias conforman vínculos que establecen relaciones contingentes y no predeterminadas entre sujetos. Con lo cual, el

${ }^{8}$ Ernesto Laclau, Nuevas reflexiones sobre la revolución de nuestro tiempo, Buenos Aires, Nueva Visión, 2000, 144.

${ }^{9}$ Desarrollos del concepto de "articulación" se encuentran en Ernesto Laclau y Chantal Mouffe, Hegemonía y estrategia socialista, Buenos Aires, Siglo XXI, 2010 y David Howarth, "Aplicando la Teoría del Discurso: El Método de la Articulación”, Studia Politicae, 5, Córdoba, 2005, 37-88.

${ }^{10}$ Chantal Mouffe, El retorno de lo político, Buenos Aires, Paidós, 1999, 112. 
concepto de "articulación" adquiere centralidad para nuestro análisis por cuanto nos permite reparar en el carácter precario de las identidades y en la imposibilidad de fijación de cualquier sentido a ninguna literalidad última. A partir de ello, comprendemos a la lucha de la AMPM como el resultado de un proceso de construcción y articulación política contingente. Analizar a las Madres desde esta perspectiva supone considerar que el carácter abierto e incompleto de su identidad habilita la conformación de diferentes procesos de resignificación mediante los cuales se definen y redefinen los contenidos y referentes de su lucha. En este apartado indagaremos en la nueva etapa de lucha contra la impunidad que conforma el organismo en oposición y rechazo a los sentidos que estructuró a la configuración política de los primeros años de reconstrucción democrática.

Como ha sido señalado, la derrota de la guerra de Malvinas (1982) precipitó el derrumbe del gobierno militar y aceleró el período de transición política. ${ }^{11}$ Inmersa en un contexto de aguda crisis económica y de importantes denuncias hacia los métodos represivos desarrollados por el gobierno de facto que provenían tanto de instancias internacionales como del movimiento de derechos humanos del país, la derrota se tradujo en una serie de manifestaciones sociales sin precedentes desde el inicio de la dictadura. ${ }^{12}$ En particular, dicho movimiento protagonizó manifestaciones que le otorgaron una relevancia tan inédita como impensada hasta ese momento. Destaca Sonderéguer que supo articular un espacio de participación que operó como eje de oposición ante el gobierno militar y punto de ruptura frente a la dominación autoritaria. ${ }^{13}$ Luego de Malvinas, el conflicto por los derechos humanos se intensificó y fue el más decisivo de los muchos que se plantearon en la transición. ${ }^{14}$ Numerosos actores sociales y políticos, tales como sindicatos y partidos políticos, que habían evitado hasta ese momento una definición incorporaron los reclamos de los organismos a sus agendas y movilizaciones. En este escenario, la resistencia que establecieron las Madres hacia la dictadura cobró un protagonismo inusitado. La lucha por sus hijos trascendió definitivamente a nivel internacional, mientras que en el ámbito nacional encabezaron todas las manifestaciones en repudio a la dictadura, alcanzaron un masivo apoyo de la ciudadanía y sus demandas se constituyeron en un espacio de confluencia con múltiples sectores. ${ }^{15}$

${ }^{11}$ Federico Lorenz, Malvinas. Una guerra argentina, Buenos Aires, Sudamericana, 2009.

${ }^{12}$ Sebastián Barros, Orden, democracia y estabilidad: Discurso y política en la Argentina entre 1976 y 1991, Córdoba, Alción, 2002; María del Carmen Feijóo y Mónica Gogna, "Las mujeres en la transición a la democracia", Elizabeth Jelin (comp.), Ciudadanía e identidad: Las mujeres en los movimientos sociales latino-americanos, Ginebra, UNRISD, 1987, 129-188; Elizabeth Jelin (comp.), Los nuevos movimientos sociales: Derechos humanos, obreros, barrios, Buenos Aires, Centro Editor de América Latina, 1985.

${ }^{13}$ María Sonderéguer, "Aparición con vida: El movimiento de Derechos Humanos en Argentina", Elizabeth Jelin (comp.), op. cit., 7-35.

${ }^{14}$ Marcos Novaro y Vicente Palermo, La dictadura militar 1976/1983: Del golpe de Estado a la restauración democrática, Buenos Aires, Paidós, 2003.

15 Gorini, op. cit. 
Durante la transición, las Madres manifestaron su apoyo y conformidad hacia Raúl Alfonsín, líder del partido Unión Cívica Radical y quién sería electo presidente de la Nación (1983-1989). Este apoyo estuvo fundamentado en la articulación que propuso el mandatario de la problemática de los derechos humanos con un proyecto político centrado en la noción de "democracia". Esto es, Alfonsín no sólo se conformó como la única posición política capaz de dar respuesta a los reclamos de verdad y justicia del movimiento de derechos humanos, sino que además constituyó a los derechos humanos y a la democracia como nombres contiguos de una misma causa. ${ }^{16}$ Así, la asunción del nuevo presidente despertó una serie de expectativas en el organismo y la necesidad de repensar su lucha en un nuevo contexto: "Este es uno de los momentos más difíciles para las Madres porque tenemos que aprender una manera de luchar y de mantenernos en la plaza pero nuestro enemigo ya no estará en la casa de gobierno". ${ }^{17}$

En las primeras semanas de gobierno Alfonsín implementó una serie de medidas tendientes a resolver la problemática de los derechos humanos. Derogó la ley de "Pacificación Nacional" sancionada por los militares, decretó la apertura de los juicios a los responsables de la violencia y las violaciones a los derechos humanos cometidos en dictadura y ordenó la creación de la Comisión Nacional sobre Desaparición de Personas (CONADEP), quién tuvo por objeto esclarecer los hechos relacionados con la desaparición de personas ocurridas en el país. Todo ello, articulado en un discurso en el que la violencia del pasado, las muertes y las desapariciones fueron interpretadas como el resultado de "la violencia espasmódica del terrorismo subversivo y de [una] represión indiscriminada con su secuencia de muertos y desaparecidos". ${ }^{18}$ Es decir, Alfonsín sería el principal enunciador de lo que se denominó "la teoría de los dos demonios". Ésta proponía una reinterpretación del pasado que, recogiendo ciertas representaciones sobre la vigencia política y la represión

\footnotetext{
${ }^{16}$ Mercedes Barros, "Los derechos humanos, entre luchas y disputas", María Bonetto, y Fabiana Martínez (comps.), Política y desborde. Más allá de una democracia liberal, Villa María, Editorial Universitaria Villa María, 2012, 43-74. Al respecto, Aboy Carlés destaca que el discurso de Alfonsín definido alrededor de la noción de "democracia" constituyó una frontera política que marcó una ruptura con el pasado reciente de violaciones a los derechos humanos, a la vez que articuló una enunciación crítica respecto de ese pasado. Cuestión que lo mostró dispuesto a impulsar una revisión de lo acontecido durante la dictadura bajo la promesa de que no habría impunidad para los crímenes cometidos, al mismo tiempo que lo posicionó en una clara distancia respecto del gobierno militar y de las prácticas violentas. Gerardo Aboy Carlés, Las dos fronteras de la democracia argentina: La reformulación de las identidades políticas de Alfonsín a Menem, Buenos Aires, Homo Sapiens, 2001. Para un mayor desarrollo de este discurso véase Ariana Reano y Julia Smola, Palabras políticas: Debates sobre la democracia en la Argentina de los ochenta, Buenos Aires, Undav Ediciones/UNGS Ediciones, 2014.

${ }^{17}$ Hebe de Bonafini citada en La Razón, 18-11-1983.

18 Raúl Alfonsín, "Mensaje a la Honorable Asamblea Legislativa, el día 10 de diciembre de 1983", Discursos presidenciales (10-12-1983 a 23-03-1984), Buenos Aires, Secretaría de la Información Pública, 1988.
} 
que circulaban en la Argentina en la década del setenta, establecía que las violaciones a los derechos humanos debían ser entendidas en un contexto de enfrentamiento entre dos terrorismos: el de extrema izquierda y el de extrema derecha. ${ }^{19}$ De aquí que el mandatario puso en manos de la justicia la tarea de evitar la impunidad de los culpables mediante la orden de procesamiento de los líderes guerrilleros y de las cúpulas de las tres primeras Juntas Militares. Asimismo, la CONADEP estuvo integrada por una serie de reconocidas personalidades que garantizarían el trabajo de manera independiente de la conflictividad social y del movimiento de derechos humanos. ${ }^{20}$

Tanto los términos de la revisión del pasado que propuso Alfonsín como las políticas que implementó en este marco pronto comenzaron a desvanecer las expectativas de las Madres. En un período muy breve de tiempo, la lucha en el nuevo contexto comenzó a definirse en disputa con las medidas propuestas por el gobierno. Así, el organismo cuestionó tanto el objetivo de la CONADEP como su informe final por cuanto consideraron que el énfasis de la investigación en las víctimas de la violencia y los abusos implicaba una invisibilización de los responsables de dichas atrocidades. ${ }^{21}$ También confrontaron con los términos de los procesos judiciales y la lectura "emplead[a] por el Gobierno que intenta equiparar a [sus] hijos con los represores de éstos infamantes años". ${ }^{22}$ En su lugar, en conjunto con los demás organismos de derechos humanos, las MPM demandaban el establecimiento de una Comisión Parlamentaria Bicameral con plenos poderes para

${ }^{19}$ Vera Carnovale, "Memorias, espacio público y Estado: La construcción del Museo de la Memoria", Estudios AHILA en Historia Latinoamericana, 2, 2006; Marina Franco, "La "teoría de los dos demonios' en la primera etapa de la posdictadura", Claudia Feld y Marina Franco (comp.), Democracia, hora cero. Actores, políticas y debates en los inicios de la posdictadura, Buenos Aires, Fondo de Cultura Económica, 2015, 23-80 y Hugo Vezzetti, Sobre la violencia revolucionaria. Memorias y olvidos. Buenos Aires, Siglo XXI, 2013.

${ }^{20}$ Roberto Gargarella, "Democracia y derechos en los años de Alfonsín", Roberto Gargarella, María Murillo y Mario Pecheny (comps.), Discutir Alfonsín. Buenos Aires, Siglo XXI, 2010 y Marcos Novaro, "Formación, desarrollo y declive del consenso alfonsinista sobre derechos humanos", Roberto Gargarella, María Murillo y Mario Pecheny (comps.), Discutir Alfonsín, Buenos Aires, Siglo XXI, 2010. Para un análisis más detallado de la CONADEP y de los conflictos que tuvieron lugar durante los años de democracia en torno a la construcción de memoria(s) respecto de Informe Final "Nunca Más" realizado por dicha Comisión véase Emilio Crenzel, $L a$ historia política del Nunca Más. La memoria de las desapariciones en la Argentina, Buenos Aires, Siglo XXI, 2014.

${ }^{21}$ Cabe destacar que la creación de la CONADEP generó un debate al interior del MDH que concluyó en diversas posiciones. En tanto que algunos organismos como Abuelas de Plaza de Mayo entregaron documentación recabada durante la dictadura, algunos miembros de otros organismos como la Asamblea Permanente por los Derechos Humanos y el Centro de Estudios Legales y Sociales optaron, sin deponer sus reclamos, por participar de la investigación. Por su parte, otros, como el Servicio de Paz y Justicia, condicionaron su participación, mientras que las MPM se opusieron abiertamente.

${ }^{22}$ Madres de Plaza de Mayo, Carta Abierta al país, 01-03-1984. 
investigar la política represiva de la dictadura en la que tenga participación el movimiento y la reglamentación de una Ley de Instalación de Juicio por Jurados para la determinación de las condenas a los crímenes cometidos. Asimismo, y como consecuencia de este posicionamiento crítico, se negaron a participar de los procesos judiciales, rechazaron recibir huesos de cadáveres y se opusieron a la inhumación de tumbas y fosas con NN que arrojaban como conclusión la “'muerte por enfrentamiento', fecha, lugar y área operativa". ${ }^{23}$ Sobre ello, una madre comenta:

Nosotras sabíamos que miles de desaparecidos habían sido en secreto asesinados $\mathrm{u}$ enterrados. Las exhumaciones no nos decían nada que nosotras no supiésemos... No estábamos de acuerdo con la exhumación de los cuerpos. Con la exhumación ellos querían erradicar el problema de los desaparecidos, porque entonces no eran más desaparecidos, sólo personas muertas. Nosotras no queremos el nombre de las víctimas. Nosotras sabemos quiénes eran. Nosotras queremos el nombre de los asesinos. Nosotras queremos que nos digan lo que pasó. Ellos tienen que explicarnos lo que no quieren explicarnos. Este es el sentido de la "Aparición con Vida". Nosotras respetamos a aquellas madres que quieren la exhumación desde luego, pero nosotras no estamos, como organización, de acuerdo con ello. ${ }^{24}$

El descontento que produjo entre las integrantes del organismo el fallo del juicio a las juntas militares y la oposición que manifestaron hacia las leyes de Punto Final y Obediencia Debida profundizó la confrontación entre las Madres y Alfonsín de manera tal que pusieron en duda la ruptura con el pasado que éste decía encarnar. De este modo, el organismo radicalizó su lucha a partir de la articulación de una lectura que trazó una línea continuidad entre la última dictadura y la democracia alfonsinista. En sus términos, "Alfonsín alcanzó el gobierno pero los militares mantienen el poder", "la justicia es la misma y cómplice del

23 Madres de Plaza de Mayo, gacetilla de prensa, Buenos Aires, 16-04-1984. Con la asunción de Alfonsín a la presidencia de la Nación el 10 de diciembre de 1983 los medios de comunicación comenzaron a dar cuenta de la política represiva implementada por el gobierno de facto de un modo inédito hasta ese entonces. Las cientos de tumbas NN encontradas a lo largo de todo el país a través de denuncias de particulares que llegaban a la justicia ocuparon un lugar central en las noticias. Numerosos centros clandestinos de detención comenzaron a ser reconocidos por detenidos sobrevivientes y se difundieron masivamente sus testimonios respecto de lo acontecido durante el cautiverio. Véase Pilar Calveiro, Poder y desaparición, Buenos Aires, Colihue, 1998 y Claudia Feld, "La prensa de la transición ante el problema de los desaparecidos: el discurso del "show del horror", Claudia Feld y Marina Franco (comp.), Democracia, hora cero. Actores, políticas y debates en los inicios de la posdictadura, Buenos Aires, Fondo de Cultura Económica, 2015, 269316.

${ }^{24}$ Citado en Eugene Gogol, El concepto del "otro" en la liberación latinoamericana: La fusión del pensamiento filosófico emancipado y las revueltas sociales, Buenos Aires, Ediciones Herramienta, 2007, 295.

${ }^{25}$ Madres de Plaza de Mayo, Boletines Informativos No 18 y 19/20, 1984. 
Proceso de Reorganización Nacional", 26 "no se encuentran detenidos esos responsables, confirmados manteniendo sus cargos o participando de actos oficiales". 27

Por lo tanto, la revisión del pasado más reciente que llevó adelante Raúl Alfonsín y las políticas en materia de derechos humanos que se derivaron de ella fueron resistidas por las Madres dando lugar a la emergencia de una nueva etapa de lucha contra la impunidad que no sólo se definió en confrontación con dichas medidas, sino también en rechazo a los sentidos que otorgaban significación a la configuración política aquel entonces. Esto implicó la radicalización de su posicionamiento en el orden social y la emergencia de un proceso de reconfiguración identitaria que será consolidado durante la década siguiente.

Ahora bien, este posicionamiento y radicalidad pronto afectaron la relevancia que las Madres habían adquirido en la resistencia a la dictadura y durante el período de transición. El gobierno nacional deslegitimó su posicionamiento y las colocó en la esfera de la irracionalidad y la manipulación política por parte de los "enemigos de la democracia". Con lo cual, "antinacionales", "antidemocráticas", "desestabilizadoras", "anticonstitucionales", "ultraizquierdistas" fueron los calificativos que comenzaron a sonar con mayor eco en el país para nombrarlas y para responder a cada una de sus críticas. En estrecha relación con ello, se produjo una progresiva pérdida de convocatoria y capacidad de articulación por parte de las Madres que no sólo se tradujo en una disminución del consenso de la ciudadanía en torno a su lucha, sino además, en la fisura de las solidaridades que el organismo había establecido con diferentes sectores sociales y políticos y con los mismos organismos de derechos humanos. ${ }^{28}$ Finalmente, el número de madres que marchaba cada jueves en la Plaza de Mayo también comenzó a disminuir a medida que se radicalizaba la confrontación con el Estado. La forma que adquirió la nueva etapa de lucha estuvo en el centro de las discusiones entre las integrantes hasta producirse la división del organismo a mediados de 1986 y, con ello, la conformación de las Madres de Plaza de Mayo Línea Fundadora y de la Asociación Madres de Plaza de Mayo -constituida, ésta última, por las madres que defendieron la radicalidad descripta-.

Esta lectura deslegitimatoria y crítica tuvo sus repercusiones y reapropiaciones en los ámbitos académicos, principalmente en aquellos espacios preocupados por analizar el devenir de los nuevos movimientos sociales constituidos durante la dictadura en el período de democracia. Así, algunos escritos comenzaron a enfatizar en la radicalización de la lucha

${ }^{26}$ Madres de Plaza de Mayo, Boletín Informativo No 19/20, 1984, 16.

${ }^{27}$ Ibid, 2.

${ }^{28} \mathrm{Si}$ bien todos los organismos compartían el descontento con el fallo judicial y comenzaban a vislumbrar los primeros indicios de la claudicación de Alfonsín respecto de la causa de los derechos humanos, las discrepancias emergían en la definición de la forma y los límites de la confrontación con el gobierno y en el establecimiento de los modos de lucha ante dicha claudicación. Véase Ulises Gorini, La otra lucha: Historia de las Madres de Plaza de Mayo (1983-1986). Buenos Aires, Norma, 2008; Elízabeth Jelin, "Certezas, incertidumbres y búsquedas: el movimiento de derechos humanos en la transición", en Feld, Claudia y Franco, Marina (comp.), Democracia, hora cero. Actores, políticas y debates en los inicios de la posdictadura. Buenos Aires, Fondo de Cultura Económica, 2015, 195-224. 
de las Madres y en el avance de un discurso antidemocrático dentro del organismo. ${ }^{29}$ En términos de estos análisis, las Madres pierden fuerza y legitimidad debido a que erróneamente incorporan consignas políticas de la extrema izquierda y desaprovechan el lugar que la democracia les otorgaba. Y es precisamente en el desacierto de esta incorporación que estos análisis comprenden las desarticulaciones entre las Madres y otros sectores sociales y políticas con los que conformaron la resistencia a la dictadura años atrás. Al respecto, Héctor Leis subraya que más allá que durante aquel momento el organismo comenzó a reivindicar la lucha de sus hijos detenidos-desaparecidos y que ello aludía implícitamente a la revolución,

está la cuestión de transformar la causa de los derechos humanos en vanguardia de las luchas populares contra el sistema de dominación "burgués", de ubicarse en el escenario como movimiento político antes que como movimiento social. Haber permitido esto es el error más grave de las Madres y, en general, del movimiento de derechos humanos. ${ }^{30}$

En un estudio posterior, Marcos Novaro ${ }^{31}$ vuelve sobre el período en cuestión para interrogarse por el proceso paulatino mediante el cual el movimiento de derechos humanos en la Argentina se volvió más impermeable a las opciones políticas elegidas por el gobierno de Alfonsín y a las nociones liberal-republicanas sobre los derechos que les otorgaron significación. Como respuesta, el autor considera que el hundimiento del consenso alfonsinista entre democracia y derechos humanos que tuvo lugar luego de finalizado el juicio a las Juntas Militares tiene mucho que decir al respecto. Además de ello, nos interesa destacar que la progresiva pérdida de relevancia del lenguaje de derechos humanos que se produjo en el discurso de las Madres hacia finales de la década del ochenta implicó un proceso de resignificación de su lucha que se constituyó en disputa con los sentidos que definían a la democracia en aquel momento.

Esto es, consideramos necesario problematizar aquellas lecturas que enfatizan en la radicalidad que adquirió el posicionamiento que adoptaron las MPM ante el gobierno constitucional y que fundamentan en ella la pérdida de protagonismo del organismo y la emergencia de un discurso antidemocrático. Las Madres no rechazaron la democracia como forma de gobierno y organización social, sino que confrontaron con los contenidos que había adquirido en la configuración alfonsinista, con la forma en que el concepto de democracia y la causa por los derechos humanos fueron articulados en un discurso oficial que interpretaba la violencia de los años pasados en el marco de la teoría de los dos demonios. Fueron precisamente los rechazos a estos sentidos los que fundamentaron la oposición al alfonsinismo, los que reconstituyeron su lucha en una lucha contra la impunidad, los que radicalizaron el posicionamiento del organismo en el orden sociopolítico $\mathrm{y}$, como veremos en el próximo apartado, los que habilitaron el

\footnotetext{
${ }^{29}$ Pereyra, op. cit.

${ }^{30}$ Leis, op. cit., 53-54. Para otro análisis en estos términos véase Brocatto, op. cit.

${ }^{31}$ Novaro, op.cit., 41-65.
} 
establecimiento de relaciones de articulación con luchas de sectores populares vinculadas a la militancia de izquierda.

\section{3. "Giro a la izquierda" y precariedad en la lucha contra la impunidad}

Luego de la división de las Madres durante 1986, la AMPM reiteró la lucha contra la impunidad emergente en los primeros años de retorno a la democracia en la formación política que hegemonizó la década del noventa. Esta reiteración estuvo caracterizada por una operación en la que los términos de su lucha se redefinieron en oposición al concepto que articuló a dicha hegemonía, a saber, el concepto de "pacificación nacional".

La profunda crisis económica y política que condicionó la salida anticipada de Alfonsín del gobierno en el año 1989 habilitó la conformación de una configuración social que, bajo el liderazgo del peronismo renovador encarnado en la figura de Carlos Menem, presentó a la "pacificación nacional" como el principal punto de articulación; como el camino para alcanzar la estabilidad democrática y económica amenazada por las sublevaciones militares y la hiperinflación. Así, este concepto implicó la reconciliación del pueblo argentino dividido a la vez que fundamentó los decretos de indultos a represores de la última dictadura y las leyes de reparación económica a las víctimas del terrorismo de Estado. Con lo cual, "lejos de otorgarle centralidad, en la nueva formación política la demanda de los derechos humanos era desplazada del campo de lo legítimo, ocupando una posición cada vez más marginal y relegada". 32

A su vez, la lectura que realizó el gobierno de Menem (1989-1999) respecto de la crisis económica y las soluciones que propuso se desprendieron igualmente del concepto de "pacificación nacional". En este punto, Sebastián Barros ${ }^{33}$ sostiene que mientras el discurso alfonsinista emergente con el retorno de la democracia le atribuyó la responsabilidad por los problemas económicos del país a las políticas económicas liberales establecidas por la dictadura militar, durante los dos últimos años de su mandato emergió una lectura que atribuyó dicha responsabilidad a la crisis de un modelo económico intervencionista que se resistía a las transformaciones demandadas por la sociedad argentina. En el mismo momento en que la interpretación de la crisis se redefinía en estos términos, el nuevo plan económico del líder peronista era presentado en oposición a aquel modelo que retardaba el desarrollo del potencial económico del país. Así, la "pacificación nacional” funcionó como el elemento que le permitiría a la Argentina desplegar todas sus potencialidades en el futuro a través del establecimiento del programa económico neoliberal que se sintetizó en los siguientes puntos: implementación del sistema de convertibilidad de la moneda, desregulación de los mercados, privatización de las empresas y servicios públicos, reforma fiscal, integración regional, apertura de la economía argentina al mercado mundial y

32 Mercedes Barros, "Democracia y Derechos Humanos: Dos formas de articulación política en Argentina”, E-L@tina Revista electrónica de estudios latinoamericanos, 29, 8, Argentina, 2009, 11.

${ }_{33}$ Sebastián Barros, "Las continuidades discursivas de la ruptura menemista", Francisco Panizza (comp.), El populismo como espejo de la democracia, Buenos Aires, Fondo de Cultura Económica, 2009, 351-381. 
equilibrio del presupuesto del gobierno mediante la reducción del gasto público y el aumento de los ingresos. ${ }^{34} \mathrm{Si}$ bien no nos detendremos en los cambios en la estructura social que se produjeron como consecuencia de la implementación de estas políticas, nos interesa subrayar que el incremento de la desigualdad y la exclusión social se constituyeron en un punto central para comprender las relaciones que estableció la AMPM con grupos militantes de la década del setenta y con espacios de lucha vinculados a sectores políticos de izquierda.

Respecto de dicho proceso, destacamos la importancia que adquirió en la AMPM la confrontación con el discurso menemista en torno tanto a la revisión del pasado más reciente como al proyecto económico neoliberal implementado. Por lo cual, la resistencia conformada contra la dictadura continuó. Continuó en el contexto de la "pacificación nacional" y continuó, además, en el marco de una serie de alteraciones que se produjeron en las luchas por los derechos humanos en esta configuración social. En este sentido, Mercedes Barros sostiene que principalmente hacia mediados de la década del noventa la lucha por los derechos humanos se definió en oposición a la impunidad del pasado más reciente a la vez que los crímenes cometidos por el terrorismo de Estado comenzaron a ser concebidos con más fuerza como la consecuencia de la imposición en el país de un proyecto político y económico de exclusión social que perduraba hasta ese entonces. ${ }^{35}$

Con lo cual, los desaparecidos comienzan a ser definidos como jóvenes revolucionarios que fueron asesinados por luchar en contra de la desigualdad y la injusticia social en el país mientras que la política neoliberal implementada por el gobierno fue percibida como la continuidad y la confirmación del plan económico iniciado en los años de dictadura:

Trazando entonces una línea de continuidad con el pasado, los ideales de esos jóvenes eran recuperados y considerados como todavía legítimos frente a la realidad del presente. Y es así como en contra de ese pasado/presente común, la lucha por los derechos humanos se unía a la lucha de aquellas generaciones de militantes de los años setenta. Los reclamos de justicia, de verdad y memoria, eran entonces articulados a una posición política particular, a un proyecto político popular de izquierda que tenía sus orígenes en los años previos a la dictadura. ${ }^{36}$

En este marco, se afianza en el discurso de la AMPM la lectura que considera la implementación del proyecto neoliberal como la causa de las detenciones y desapariciones de los 30.000, a la vez que se consolida la definición de sus hijos en términos de militantes políticos opositores al proyecto de injusticia, desigualdad y vaciamiento del Estado

\footnotetext{
${ }^{34}$ Para un mayor desarrollo de las políticas neoliberales implementadas en la Argentina véase Atilio Borón, "El experimento menemista, neoliberalismo, pobreza y democracia en la Argentina contemporánea", Buenos Aires, UBA, 1992 y Alberto Bonnet, La hegemonía menemista: El neoconservadurismo en Argentina, 1989-2001, Buenos Aires, Prometeo, 2008.

${ }^{35}$ Mercedes Barros, op. cit.

${ }^{36}$ Mercedes Barros, op. cit., 3.
} 
implementado por las Juntas Militares y continuado por los gobiernos constitucionales. Con lo cual, en la definición de sus hijos como militantes y opositores políticos que habían sido secuestrados y asesinados durante la dictadura se inscriben sus ideales de lucha. Se los significa como jóvenes revolucionarios que luchaban por una sociedad más justa y la reivindicación de su lucha implicará, a su vez, la reivindicación de su compromiso político y social que aún permanecía vigente en diversos espacios. ${ }^{37}$ De este modo, la significación de los desaparecidos en estos términos incorpora en la continuidad de la resistencia llevada adelante por la AMPM la continuidad de la lucha de sus hijos a partir del levantamiento y la reivindicación de sus banderas. Respecto de ello, destaca Bonafini:

Hemos reivindicado los objetivos revolucionarios y socialistas de nuestros hijos. Los seguimos haciendo ahora en busca de los jóvenes, también hijos nuestros, que construyan el futuro. Toda América Latina arde. Arde Nicaragua, arde Perú, arden todos los lugares donde le dicen no al capitalismo y a la injusticia. El mañana es el socialismo y no la injusticia. El mañana es el socialismo. Como lo está construyendo Cuba, que defiende su revolución frente al acecho de los canallas imperialistas. Sigamos construyendo, compañeros, la unidad para terminar con la perversión capitalista. Todos nuestros hijos, presentes hoy en nuestra Plaza, los 30.000, nos acompañan en esta lucha". ${ }^{38}$

Cada uno [de nuestros hijos] como una hormiga, o como una avejita, construía desde su lugar algo. Todos tenían una ideología firme, la ideología de la liberación, de un país más justo y solidario, la ideología de un hombre nuevo [...] A los nuestros se los llevaron porque tenían una ideología firme y creían en el hombre nuevo. ${ }^{39}$

${ }^{37}$ Cabe destacar que las transformaciones en la lucha por los derechos humanos que estamos destacando aquí constituyeron un nuevo marco de recepción e inscripción de muchos de los sentidos que habían comenzado a adquirir mayor preeminencia en el discurso de la AMPM hacia finales de la década del ochenta. Esto es, en la resistencia hacia Alfonsín -y en el proceso de desprestigio y aislamiento analizado anteriormente- este organismo denunciaba las complicidades civiles con el terrorismo de Estado, la línea de continuidad entre la dictadura y la democracia a la vez que comenzó a reivindicar las ideas y militancia de los detenidos-desaparecidos. Así, destacaba Hebe Bonafini en el 11 aniversario del 24 de marzo de 1976: "Las Madres de Plaza de Mayo [...] siguen siendo el principal referente de la ética unida a la política. No sólo por su lucha y resistencia, sino también -y casi nos atreveríamos a decir fundamentalmente- porque tuvieron un coraje mayor: reivindicaron a sus hijos como lo que fueron: luchadores de su pueblo que estaban dispuestos a darlo todo, incluso la vida misma, para que haya techo, pan, justicia y dignidad para las mayorías populares”. Citado en Federico Lorenz, “¿De quién es el 24 de marzo?: Las luchas por la memoria del golpe de 1976”, Elizabeth Jelin (Comp.), Las conmemoraciones: Las disputas en las fechas 'infelices', Madrid, Siglo XXI, 2002, 80.

${ }^{38}$ Hebe de Bonafini, $11^{\circ}$ Marcha de la Resistencia, Buenos Aires, 04-12-1991.

${ }^{39}$ Hebe de Bonafini, $16^{\circ}$ Marcha de la Resistencia, Buenos Aires, 05-12-1996. 
En relación a lo dicho, destaca Federico Lorenz ${ }^{40}$ que desde el año 1991 se introduce una transformación que les otorga una identidad única a todas las víctimas del terrorismo de Estado. La condición de víctima del desaparecido pasa a un segundo plano frente a la preponderancia que adquiere la reivindicación de las causas por las cuales fueron detenidos y desaparecidos. Por lo tanto, la AMPM no sólo denuncia las atrocidades de la dictadura y demanda verdad y justicia, sino que también inscribe en la configuración social articulada alrededor de la noción de "pacificación nacional" la lucha de sus hijos y la reivindicación de su militancia, de sus prácticas y de su proyecto de país.

De este modo, en la continuidad y reiteración de la resistencia en este contexto, la lucha contra la impunidad llevada adelante por la AMPM redefine sus límites y sus sentidos. Esto es, luchar por los 30.000 desaparecidos y luchar por la vida en este contexto de pretendida reconciliación nacional y aumento de la desigualdad y la exclusión social, significará para las Madres continuar la lucha iniciada por sus hijos. Lo cual implicará luchar por y junto al pueblo, a los desocupados, a los jubilados, a los pobres e indigentes, a los desalojados, a los estudiantes, a los docentes, a los trabajadores, a los analfabetos, a las víctimas del gatillo fácil y la represión policial, a las minorías sexuales, a los pueblos originarios, en definitiva, por y junto a los que resisten y a los que cuestionan la hegemonía neoliberal. ${ }^{41}$ Por lo tanto, la lucha contra la impunidad incorporará en este contexto nuevos contenidos y referentes al redefinirse tanto en confrontación con la revisión del pasado que llevó adelante el discurso oficial como con la política económica neoliberal. Así, convocan a la $13^{\circ}$ Marcha de la Resistencia "para repudiar el hambre impuesto por este gobierno liberalmenemista y la impunidad de los milicos genocidas". 42

En este momento, la lucha implicará no sólo a los 30.000 detenidos-desaparecidos, a la denuncia y resistencia respecto del pasado reciente, sino también al pueblo, a la desigualdad, a la injusticia y a la exclusión social que padecen los sectores populares. En la reiteración de la resistencia en este contexto, la categoría "impunidad" se resignifica como efecto de la incorporación de la continuidad de la lucha de los desaparecidos de modo tal que impunidad y hambre son partes de un mismo proceso iniciado durante la dictadura y continuado por los gobiernos constitucionales. "Contra la miseria y la impunidad", "impunidad y hambre van de la mano" fueron parte de las principales consignas que definió la lucha de la AMPM durante la década del noventa y los primeros años del nuevo siglo.

En el marco de este proceso de reconfiguración identitaria que estamos analizando, la Asociación no sólo amplía los límites de su lucha hacia otros campos de demandas sino que además profundizó y expandió las articulaciones con sectores populares y organizaciones y partidos políticos de izquierda. Cuestiones, ambas, que tal como destaca Débora

\footnotetext{
${ }^{40}$ Federico Lorenz, op. cit.

${ }^{41}$ Para ampliar sobre las relaciones que establece la AMPM con diversas luchas contra el sistema neoliberal véase Borland, op. cit.; Graciela Di Marco, "Las mujeres y la política en los '90”, Beatriz Schmukler y Graciela Di Marco, Madres y democratización de la familia en la democracia argentina, Buenos Aires, Biblios, 1997, 127-150.

${ }^{42}$ Citado en Inés Vázquez, Ulises Gorini, Gerardo Nielsen, et. al, Luchar Siempre. Las Marchas de la Resistencia, 1981-2006, Buenos Aires, Ediciones Madres de Plaza de Mayo, 2007, 73.
} 
D’Antonio, ${ }^{43}$ propiciaron una nueva apropiación del escenario político por parte de las Madres y una nueva visibilización de su lucha como un núcleo de trabajo político prestigioso en el que otros sectores sociales podían ampararse para dar curso a sus propios reclamos. ${ }^{44}$ Pero a su vez, nos interesa destacar que en el marco de las alteraciones en la lucha por los derechos humanos que tienen lugar en este momento y de la profundización de las relaciones de solidaridad con sectores de izquierda, la radicalidad que comenzó a definir la lucha e identidad de la AMPM hacia finales de la década anterior se nutre con mayor fuerza del lenguaje político de estos sectores. De esta manera, a la vez que la resistencia se reconstituye en una resistencia contra la opresión capitalista ejercida desde el Estado, semana a semana aumentan los espacios compartidos con el Movimiento Todos por la Patria, la Corriente Clasista Combativa, el Movimiento Patriótico Revolucionario Quebracho, los Movimientos de Trabajadores Desocupados (Piqueteros) y los partidos políticos Polo Obrero, Movimiento Socialista de los Trabajadores, Partido Comunista, Partido Comunista Revolucionario de la Argentina, entre otros. Asimismo, a nivel internacional la AMPM articula con el Ejército Zapatista de Liberación Nacional (México), el Movimiento Sin Tierra (Brasil) y el Movimiento Revolucionario Túpac Amaru (Perú).

Ahora bien, como parte de este proceso de resignificación de la lucha contra la impunidad que estamos analizando, cabe destacar que la socialización de la maternidad ${ }^{45}$ también se redefinen en este momento. Así, las Madres ya no serán sólo las madres de todos los detenidos-desaparecidos, sino que se conformarán en las "madres del pueblo":

${ }^{43}$ Débora D’Antonio, "Las Madres de Plaza de Mayo y la maternidad como potencialidad para el ejercicio de la democracia política", Marina Bravo, Fernanda Gil Lozano y Valeria Pita (comps), Historias de luchas, resistencias y representaciones. Mujeres en la Argentina, siglos XIX y XX, Tucumán, Edunt, 2007, 283-303.

${ }^{44}$ Cuando el plan económico menemista comenzó a ponerse en marcha, y en un contexto de primeras manifestaciones de protestas hacia éste, la AMPM inició un período de manifestaciones contra la miseria y la impunidad. Se manifiestaron en solidaridad y apoyo con todas ellas a la vez que comenzaron a tomar como propias sus demandas. Así, repudiaron el genocidio aborigen, el hambre y la Ley de Educación. Encabezaron marchas federales y junto a numerosas organizaciones de derechos humanos, movimientos sociales, estudiantiles, sindicales y políticas se movilizaron contra la Corte Suprema de Justicia. Apoyaron reclamos mineros en Santa Cruz, docentes de todo el país, cortes de rutas, tomas de tierras y demandas por trabajo, dignidad y justicia. Denunciaron violaciones de los derechos humanos en toda la Argentina. Al mismo tiempo, se multiplicaron los grupos de apoyo a las Madres en diferentes países del mundo. Por su parte, ellas apoyaron el levantamiento del pueblo en Chiapas, la demanda de independencia del país Vasco, la soberanía cubana, las manifestaciones zapatistas, el Movimiento Sin Tierra y de Madres de hijos Secuestrados en Brasil, las organizaciones de desocupados y presos políticos de Austria, el reclamo de familiares de detenidos en Alemania, España y Dinamarca, las denuncias de mujeres opositoras en Israel, la detención en Pinochet, entre otros.

${ }^{45}$ La "socialización de la maternidad", como las Madres lo denominan, implica un proceso por el cual en el desarrollo de la búsqueda colectiva de sus hijos se constituyen en las Madres de todos los desaparecidos, se asumen como las Madres de los 30.000. De este modo, no sólo son paridas por sus hijos, sino que además poseerán hijos que no fueron paridos por el vientre. 
"Yo les digo que las Madres, mientras tengamos vida, mientras tengamos un soplo de aliento, vamos a seguir luchando por la vida de nuestro pueblo. Por nuestro pueblo, para nuestro pueblo, junto a nuestro pueblo". ${ }^{6}$

De esta manera, las nuevas vidas antes mencionadas que se inscriben en el discurso de las Madres redefinen los límites de la lucha, esto es, redefinen la delimitación de las vidas por las cuales luchar, demandar y resistir. Lo que en particular nos interesa rescatar de lo dicho, reside en que este proceso de socialización de la maternidad que devino en una lucha que las posiciona como "madres del pueblo" y como "madres revolucionarias", y que las habilita a establecer lazos con aquellos excluidos o desplazados a los márgenes del sistema, implica una lucha por aquellas vidas inducidas a un estado de precariedad maximizada y producida políticamente. O dicho de otro modo, la precariedad definirá los límites de lucha, y en este sentido, definirá las "vidas" por las cuales llevar adelante la lucha.

Al hablar de "precariedad" retomamos las conceptualizaciones de Judith Butler. Al considerar a los sujetos en su constitución discursiva, la autora repara en la condición generalizada de interdependencia en la cual toda vida está siempre puesta en las manos de otro. ${ }^{47}$ En el marco de lo que denomina "ontología social corporal", la autora comprende dicha exposición corporal bajo los conceptos de "precariedad" y "precaridad". El primero de ellos -precariousness-, visibiliza una condición ontológica compartida por toda vida humana: la vulnerabilidad que proviene de nuestra dependencia a los otros y de nuestra sujeción a diversos marcos normativos. El segundo, estrechamente relacionado al anterior, evidencia ciertas condiciones de desposesión -precaridad [precarity]-producidas política y económicamente, que exponen a ciertas poblaciones en particular a una indefensión maximizada. En otras palabras, Butler distingue dos formas de desposesión que se intersecan y caracterizan a los cuerpos: una desposesión ontológica y otra claramente política que pone de manifiesto que esta común vulnerabilidad no se halla repartida de modo homogéneo entre todos los seres humanos, sino que nos encontramos con una distribución desigual del acceso a determinadas libertades y derechos. En efecto, la distinción da cuenta de una distribución diferencial de la vulnerabilidad que está ligada con el acceso desigual a la salud, al trabajo y a la educación, y que condiciona también toda una política del duelo público: tales procesos de precarización redundan en que algunas vidas valgan más que otras, en que algunas muertes resulten completamente irrelevantes. En este sentido, no toda vida es destinataria de la protección que merece, mientras que ciertas vidas están altamente protegidas, otras ni si quiera son merecedoras de duelo. Así, la distinción entre las dos formas de desposesión expresa en otros términos la estrecha relación entre los conceptos de precariedad y precaridad: mientras que la primera de ellas, en tanto categoría igualmente compartida por todas las vidas humanas no se puede revertir, los "modos diferenciales de distribuir la precariedad, de asignar la condición de descartable

\footnotetext{
${ }^{46}$ Hebe de Bonafini, Buenos Aires, 30-05-1998.

${ }^{47}$ Judith Butler, Marcos de guerra: Las vidas lloradas, Buenos Aires, Paidós, 2010.
} 
[disposability], son claramente los objetivos y efectos de las formas neoliberales de la vida social y económica". 48

La lucha de las Madres en los noventas es una lucha por aquellas vidas precarizadas en el sentido político en que Butler propone; por aquellas vidas amenazadas y violentadas por el sistema neoliberal y las políticas implementadas desde el Estado, que sufren la carencia de soportes sociales, sanitarios, jurídicos y económicos, quedando marginadas y expuestas a enfermedades, pobreza, hambre, desocupación, analfabetismo, etc. Y es precisamente en este marco de lucha y de apertura del proceso de socialización de la maternidad a la maximización de la desposesión, en donde emergen y adquieren sentidos las relaciones de articulación entre las Madres y los movimientos piqueteros, docentes, estudiantes, jubilados, familiares de víctimas de la represión policial y el gatillo fácil, colectivos sexo-genéricos, aborígenes, etc. Así, en un contexto en el que los derechos humanos fueron desplazados a los márgenes por el discurso oficial, la AMPM luchará desde estos márgenes, por los márgenes y junto a quienes habitan los márgenes:

No olvidemos que este triste capítulo de nuestra historia empezó con la siniestra dictadura asesina de 1976. Las Madres, cuando asumimos el compromiso de ser Madres de todos los detenidos desaparecidos, que nos costó a cada una diferentes tiempos, lo analizamos mucho. Cuando decidimos levantar sus banderas de lucha y hacernos revolucionarias, sabíamos lo que esto representaba. No hicimos nada sin estar convencidas de ello. Nuestro mayor compromiso es con los 30.000, con su lucha que hicimos nuestra, con el pueblo que está marginado y violentado en sus derechos más elementales. ${ }^{49}$

De este modo, la lucha contra la impunidad se redefine en una lucha contra el sistema que hegemoniza la formación política en la que viven. Se consolida aquí una lucha por la revolución, por el socialismo y por los "desaparecidos del sistema":

En 1981, nuestra primera marcha, solitas, 70 madres en la noche, rodeadas de 300 milicos resistimos por primera vez en la época de la dictadura. Y la consigna fue Aparición con Vida. Y Aparición con Vida tiene vigencia hoy porque todavía desaparecen compañeros. Porque el año pasado desaparecieron Bru, Nuñez, Guardati. Y esa consigna tiene vigencia hoy para tantos que son desaparecidos también del sistema. Y Aparición con Vida como cuestionamiento al sistema represivo que utilizaron los milicos. ${ }^{50}$

Respecto del concepto de "desaparecidos del sistema", Bonafini también expresa:

\footnotetext{
${ }^{48}$ Judith Butler y Athena Athanasiou, Dispossesion: The performative in the political, Reino Unido, Polity Press, 2013, 20-21. La traducción es nuestra.

${ }^{49}$ Evel de Petrini -AMPM-, Buenos Aires, 15-11-2001.

${ }^{50}$ Hebe de Bonafini, $14^{\circ}$ Marcha de la Resistencia, Bueno Aires, 08-12-1994.
} 
No nos debemos olvidar que todos los días nos asesinan de otra manera, nos matan de otra manera, nos someten de otra manera. Casi sin darnos cuenta, pareciera que como anestesiados, nos van quitando todo, de a poco. Y es la obra del ajuste, la obra del liberalismo, neoliberalismo... no, es la obra del capitalismo. No le pongamos otro nombre. Esto es capitalismo puro: sometimiento, explotación, marginación y expulsión de muchos del sistema. Ya muchos no contamos para el sistema. ${ }^{51}$

De este modo, refiriéndose al concepto de "desaparecidos del sistema", sostienen que "la muerte es el gran basamento del sistema [...] Los gobiernos, los sistemas económicos, tienen muchas maneras de hacer desaparecer a una persona cuando no le es políticamente útil, no sólo la que les tocó padecer a nuestros hijos". 52 Entonces, el levantamiento de las banderas de sus hijos significará para la AMPM continuar con una resistencia que como efecto de su reiteración en confrontación con la hegemonía articulada en torno a la "pacificación nacional" se desplazará hacia una lucha por las vidas que no cuentan como vidas para el sistema. Es decir, se desplazará hacia una lucha por aquellas vidas excluidas y desaparecidas del sistema, de la ciudadanía, de los términos de la sociabilidad. En otras palabras, los nuevos contenidos y referentes que se incorporan a la lucha contra la impunidad producto de su reiteración en este contexto conforma a la AMPM en un espacio de resistencia contra el sistema capitalista que hegemoniza la formación política y económica nacional y contra las diferentes formas de muerte que este sistema produce. La lucha contra la impunidad se resignifica, de este modo, en una lucha que pretende intervenir en la distribución diferencial de la precariedad y que da cuenta de que el modo en que el sistema hegemónico distribuye la precariedad no sólo vulnera los derechos más elementales del pueblo, sino que en este mismo proceso expulsa a múltiples vidas de los marcos de lo inteligible, invisibilizándolas, desapareciéndolas, condenándolas a vivir en un estado que en su discurso equivaldrá a la muerte. La lucha de la AMPM durante la década del noventa se resignifica en una lucha por la definición de las vidas -humanas-portadoras de derechos y, en este sentido, la continuidad de la resistencia en esta configuración social conforma una lucha por la ampliación de los límites que definen las vidas merecedoras de protección, por

${ }^{51}$ Hebe de Bonafini, Mar del Plata, 07-02-1997. Del mismo modo, "un pibe que se droga es un nuevo desaparecido para este sistema, porque un pibe que se droga no jode, porque un pibe que se droga poco a poco se va perdiendo" (Hebe de Bonafini, $16^{\circ}$ Marcha de la Resistencia, Buenos Aires, 05-12-1996). "La falta de trabajo es un crimen. Son criminales los empresarios que dejan sin trabajo a millones de hombres y mujeres. El terrorismo de Estado siempre está organizado por funcionarios al servicio de los grupos económicos. Ellos nos quieren convertir en esclavos. Las Madres de Plaza de Mayo creemos que los desocupados son los nuevos desaparecidos del sistema. El trabajo digno es un derecho que nadie nos puede quitar y por el que debemos luchar hasta las últimas consecuencias" (AMPM, citado en Elizabeth Borland, op. cit., 142).

${ }^{52}$ AMPM, Historia de las Madres de Plaza de Mayo, Buenos Aires, Ediciones Madres de Plaza de Mayo, 2009, 47. 
la ampliación de los límites que distinguen las vidas que importan de aquellas que no son merecedoras de llanto y duelo.

A partir de lo dicho, consideramos que la radicalidad que destaca la bibliografía respecto de la Asociación no está dada tanto por su "giro hacia la izquierda", entendemos más bien que son radicales por cuestionar los límites del sistema y demandar una ampliación de los límites de lo humano, por luchar por las condiciones que hacen que sean posibles e imposibles las vidas. Por supuesto que esto las posiciona en solidaridad con las luchas populares y movimientos sociales de izquierda y habilita procesos de articulación con estos sectores, pero más que comprender la radicalización en estos términos, y juzgar el acierto o desacierto de este hecho, consideramos que se radicalizan en tanto intervienen sobre condiciones estructurales del orden social que incluso trascienden al propio gobierno de aquel entonces.

\section{Conclusión}

A lo largo de este artículo nos propusimos volver sobre las reconfiguraciones identitarias que se produjeron en la AMPM durante las tres década de democracia que sucedieron a la última dictadura cívico-militar que tuvo lugar en la Argentina, con el doble objetivo de repensar en torno a aquellas lecturas que enfatizan en la radicalidad que caracterizó a este organismo y de indagar en un momento de lucha que no ha sido abordado en su debida profundidad y complejidad. Así, luego de presentar la perspectiva analítica que habilita nuestro análisis, nos detuvimos en el análisis de los diferentes procesos de articulación y construcción política contingente que definieron la nueva etapa de lucha contra la impunidad.

En este sentido, sostuvimos que durante los primeros años de reconstrucción democrática la radicalidad del organismo no estuvo dada tanto por su confrontación con la democracia en sí misma, sino por la disputa que establecieron con los sentidos que estructuraron la configuración política que hacía de la democracia y los derechos humanos dos nombres contiguos de una misma causa que encontró su puntos de articulación en lo que luego se denominó como la "teoría de los dos demonios". Por otra parte, indagamos luego en las condiciones que hicieron posible la conformación de relaciones entre la AMPM y sectores políticos de izquierda a la vez que reparamos en el modo en que estas articulaciones formaron parte de un proceso de reconfiguración identitaria del organismo que lo llevó a posicionarse en confrontación con las políticas de revisión del pasado promovidas por el menemismo y, en términos más generales, con el neoliberalismo y el capitalismo. En relación a este momento, consideramos su radicalidad no tanto en función de la inscripción de lenguajes políticos de izquierda en su lucha sino más bien por la conformación de una resistencia que disputó los límites del sistema mediante una lucha que se erigió en defensa de las vidas inducidas a un estado de precariedad política y económicamente maximizada.

Finalmente, entonces, centrar el análisis en el acierto o el error de la incorporación a su discurso de contenidos de luchas de izquierda al modo en que lo hacen los estudios 
mencionados anteriormente, o bien en la evaluación de qué tanto han transformado sus objetivos a partir de ello y de su confrontación con el Estado en el período democrático, ${ }^{53}$ posiciona la discusión en un terreno en el que quedan invisibilizados los diferentes procesos de articulación política contingente que significaron la lucha e identidad del organismo en el período analizado. Las lecturas que enfatizan en la radicalidad de la AMPM tienden a considerar su identidad de modo más bien homogéneo y estable. Es decir, cuestionar las relaciones que establecen con sectores de izquierda, juzgar esto como un error del movimiento que le costó la legitimación que habían alcanzado en años posteriores supone, desde nuestra perspectiva -y volviendo al interrogante planteado por Novaro respecto de la permeabilidad del movimiento de derechos humanos hacia organizaciones de izquierda y su lenguaje político-, considerar el lenguaje liberal de derechos humanos como un elemento que funda y determina al organismo más que como un contenido que forma parte de un proceso de articulación que en cuanto tal es susceptible de ser resignificado y alterado.

\section{Bibliografía}

Gerardo Aboy Carlés, Las dos fronteras de la democracia argentina: La reformulación de las identidades políticas de Alfonsín a Menem, Buenos Aires, Homo Sapiens, 2001.

AMPM, Historia de las Madres de Plaza de Mayo, Buenos Aires, Ediciones Madres de Plaza de Mayo, 2009.

Enrique Andriotti Romanin, “Actores, Estado y políticas públicas reparatorias en relación al terrorismo de Estado en Argentina (2003-2007)”. Sudamérica, 4, Mar del Plata, 2015, 136155.

Mercedes Barros, "Democracia y Derechos Humanos: Dos formas de articulación política en Argentina”, E-L@tina Revista electrónica de estudios latinoamericanos, 29, 8, Argentina, 2009, 3-18.

Mercedes Barros, "Los derechos humanos, entre luchas y disputas", María Bonetto, y Fabiana Martínez (comps.), Política y desborde. Más allá de una democracia liberal, Villa María, Editorial Universitaria Villa María, 2012.

Sebastián Barros, Orden, democracia y estabilidad: Discurso y política en la Argentina entre 1976 y 1991, Córdoba, Alción, 2002.

Sebastián Barros, "Las continuidades discursivas de la ruptura menemista", Francisco Panizza (comp.), El populismo como espejo de la democracia, Buenos Aires, Fondo de Cultura Económica, 2009, 351-381.

Alberto Bonnet, La hegemonía menemista: El neoconservadurismo en Argentina, 1989-2001, Buenos Aires, Prometeo, 2008.

Elizabeth Borland, "Las Madres de Plaza de Mayo en la era neoliberal: Ampliando objetivos para unir el pasado, el presente y el futuro". Colombia Internacional, 63, Colombia, 2006, 128147.

Atilio Borón, "El experimento menemista, neoliberalismo, pobreza y democracia en la Argentina contemporánea", Buenos Aires, UBA, 1992.

Carlos Brocato, "De la ética a la política", La Mirada, 1, 1990, 12-16.

\footnotetext{
${ }^{53}$ Para un análisis del grado de transformación de sus objetivos primeros de lucha véase Borland, op. cit.
} 
Judith Butler, Marcos de guerra: Las vidas lloradas, Buenos Aires, Paidós, 2010.

Judith Butler y Athena Athanasiou, Dispossesion: The performative in the political, Reino Unido, Polity Press, 2013.

Vera Carnovale, "Memorias, espacio público y Estado: La construcción del Museo de la Memoria", Estudios AHILA en Historia Latinoamericana, 2, 2006.

Emilio Crenzel, La historia política del Nunca Más. La memoria de las desapariciones en la Argentina, Buenos Aires, Siglo XXI, 2014.

Graciela Di Marco, "Las mujeres y la política los '90”, Beatriz Schmukler y Graciela Di Marco, Madres y democratización de la familia en la democracia argentina, Buenos Aires, Biblios, 1997, 127-150.

Débora D’Antonio, "Las Madres de Plaza de Mayo y las aperturas de un camino de resistencias. Argentina, última dictadura militar: 1976-1983", Nuestra América, 2, agosto-diciembre, 2006, 29-40.

Débora D’Antonio, "Las Madres de Plaza de Mayo y la maternidad como potencialidad para el ejercicio de la democracia política", Marina Bravo, Fernanda Gil Lozano y Valeria Pita (comps), Historias de luchas, resistencias y representaciones. Mujeres en la Argentina, siglos XIX y XX, Tucumán, Edunt, 2007.

Claudia Feld y Marina Franco (comp.), Democracia, hora cero. Actores, políticas y debates en los inicios de la posdictadura, Buenos Aires, Fondo de Cultura Económica, 2015.

Marina Franco, "La 'teoría de los dos demonios' en la primera etapa de la posdictadura", Claudia Feld y Marina Franco (comp.), Democracia, hora cero. Actores, politicas y debates en los inicios de la posdictadura, Buenos Aires, Fondo de Cultura Económica, 2015.

María del Carmen Feijóo y Mónica Gogna, "Las mujeres en la transición a la democracia", Elizabeth Jelin (comp.), Ciudadanía e identidad: Las mujeres en los movimientos sociales latino-americanos, Ginebra, UNRISD, 1987.

Ulises Gorini, La rebelión de las Madres: Historia de las Madre de Plaza de Mayo (1976-1983), Buenos Aires, Norma, 2006.

Ulises Gorini, La otra lucha: Historia de las Madres de Plaza de Mayo (1983-1986). Buenos Aires, Norma, 2008.

David Howarth, "Aplicando la Teoría del Discurso: El Método de la Articulación", Studia Politicae, 5, Córdoba, 2005.

Elízabeth Jelin (comp.), Los nuevos movimientos sociales: Derechos humanos, obreros, barrios, Buenos Aires, Centro Editor de América Latina, 1985.

Elízabeth Jelin, "Certezas, incertidumbres y búsquedas: el movimiento de derechos humanos en la transición", en Feld, Claudia y Franco, Marina (comp.), Democracia, hora cero. Actores, políticas y debates en los inicios de la posdictadura. Buenos Aires, Fondo de Cultura Económica, 2015, 195-224.

Ernesto Laclau, Nuevas reflexiones sobre la revolución de nuestro tiempo, Buenos Aires, Nueva Visión, 2000.

Ernesto Laclau y Chantal Mouffe, Hegemonía y estrategia socialista, Buenos Aires, Siglo XXI, 2010.

Héctor Leis, El movimiento por los derechos humanos y la política argentina/l, Buenos Aires, Centro Editor de América Latina, 1989.

Federico Lorenz, "¿De quién es el 24 de marzo?: Las luchas por la memoria del golpe de 1976”, Elizabeth Jelin (Comp.), Las conmemoraciones: Las disputas en las fechas 'in-felices', Madrid, Siglo XXI, 2002, 53-100. 
Federico Lorenz, Malvinas. Una guerra argentina, Buenos Aires, Sudamericana, 2009.

Soledad Montero, ;Y al final un día volvimos! Los usos de la memoria en el discurso kirchnerista (2003 -2007), Buenos Aires Prometeo, 2012.

Virginia Morales, De la cocina a la Plaza. La categoría "madre” en el discurso de las Madres de Plaza de Mayo, Villa María, Editorial Universitaria Villa María, 2010.

Virginia Morales, "Escisión y dos modos de ser Madres de Plaza de Mayo: tensión y complejidad en la socialización de la maternidad", Estudios de Género, 3:6, julio-diciembre 2017, 68-105. En prensa.

Chantal Mouffe, El retorno de lo político, Buenos Aires, Paidós, 1999.

Marcos Novaro y Vicente Palermo, La dictadura militar 1976/1983: Del golpe de Estado a la restauración democrática, Buenos Aires, Paidós, 2003.

Marcos Novaro, "Formación, desarrollo y declive del consenso alfonsinista sobre derechos humanos", Roberto Gargarella, María Murillo y Mario Pecheny (comps.), Discutir Alfonsín, Buenos Aires, Siglo XXI, 2010, 41-65.

Sebastián Pereyra, "¿Cuál es el legado del movimiento de Derechos Humanos?: El problema de la impunidad y los reclamos de justicia en los noventa", Federico Schuster, Francisco Naishtat, Gabriel Nardacchione y Sebastián Pereyra (comps.), Tomar la palabra: Estudios sobre protesta social y acción colectiva en la Argentina contemporánea, Buenos Aires, Prometeo, 2005, 151-191.

Ariana Reano y Julia Smola, Palabras políticas: Debates sobre la democracia en la Argentina de los ochenta, Buenos Aires, Undav Ediciones/UNGS Ediciones, 2014.

Martín Retamozo, "El kirchnerismo y los movimientos sociales. Lógicas políticas y hegemonía en Argentina", IX Jornadas de Sociología. Facultad de Ciencias Sociales, Universidad de Buenos Aires, 2011. Disponible en: http://www.aacademica.org/000-034/575 [Consulta: 2009-2016].

María Sonderéguer, "Aparición con vida: El movimiento de Derechos Humanos en Argentina", Elizabeth Jelin (comp.), Los nuevos movimientos sociales: Derechos humanos, obreros, barrios, Buenos Aires, Centro Editor de América Latina, 1985, 7-35.

Inés Vázquez, Ulises Gorini, Gerardo Nielsen, et. al, Luchar Siempre. Las Marchas de la Resistencia, 1981-2006, Buenos Aires, Ediciones Madres de Plaza de Mayo, 2007.

Hugo Vezzetti, Sobre la violencia revolucionaria. Memorias y olvidos. Buenos Aires, Siglo XXI, 2013.

Cristina Viano, "Trabajadora, militante y madre: una historia de vida, X Jornadas Interescuelas/Departamentos de Historia. Escurla de Historia de la Facultad de Humanidades y Artes, Universidad Nacional de Rosario, Rosario, 2005.

Cristina Viano, "Mujeres y movimientos sociales: un acercamiento a Madres de Plaza de Mayo desde una historia de vida", Gerardo Necoechea, Mariana Mastrángelo, Edna Ovalle, et. al., Historia Oral y militancia política en México y Argentina, Buenos Aires, El Colectivo, 2008.

Periódicos

La Razón, 18-11-1983.

Boletín Informativo Madres de Plaza de Mayo, núm. 18, 1984.

Boletín Informativo Madres de Plaza de Mayo, núm. 19/20, 1984.

Documentos

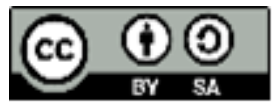


Raúl Alfonsín, "Mensaje a la Honorable Asamblea Legislativa, el día 10 de diciembre de 1983", Discursos presidenciales (10-12-1983 a 23-03-1984), Buenos Aires, Secretaría de la Información Pública, 1988.

Discurso pronunciado por Hebe de Bonafini, $8^{\circ}$ Marcha de la Resistencia, Bueno Aires, 09-121988.

Discurso pronunciado por Hebe de Bonafini, $11^{\circ}$ Marcha de la Resistencia, Buenos Aires, 04-121991.

Discurso pronunciado por Hebe de Bonafini, $14^{\circ}$ Marcha de la Resistencia, Bueno Aires, 08-121994.

Discurso pronunciado por Hebe de Bonafini, $16^{\circ}$ Marcha de la Resistencia, Buenos Aires, 05-121996.

Discurso pronunciado por Hebe de Bonafini, Mar del Plata, el 7-02-1997. Disponible URL: http://www.madres.org/asp/contenido.asp?clave=412 [Consulta: 14 de octubre de 2008].

Discurso pronunciado por Hebe de Bonafini, Buenos Aires, 30-05-1998. Disponible URL: http://www.madres.org/asp/contenido.asp?clave=426 [Consulta: 18 de diciembre de 2007].

Discurso pronunciado por Hebe de Bonafini, Buenos Aires, 26-01-2006

Discurso pronunciado por Evel de Petrini -AMPM-, Buenos Aires, 15-11-2001. Disponible URL: http://www.madres.org/asp/contenido.asp?clave=127 [Consulta: 23 de octubre de 2008].

Madres de Plaza de Mayo, Gacetilla de prensa, 16-04-1984. 